\title{
Composite Suction Foundation in Clay Subjected to Combined Loading
}

\author{
Yun-Chih Chiang, San-Shyan Lin, Sheng-Yu Chu, Hui-Ming Fang, Hsing-Yu Wang, and Sung-Shan \\ Hsiao
}

\begin{abstract}
This study is based on a simulation of suction and compound suction written in Plaxis 3D finite element software. Unlike a conventional suction foundation, a composite suction foundation has a plate-like structure in its upper part, which improves the axial and lateral bearing capacity of the foundation. In this study, sedimentation data obtained from Changhua, Taiwan are used as the inputs, and bearing capacity is evaluated for a composite suction foundation under two-directional loading. By changing the diameter of the upper plate, the length-diameter ratio of the suction bucket, and the eccentricity of the load, relevant stress behaviors of the foundation are simulated.
\end{abstract}

Index Terms - Plaxis 3D, composite suction foundation, stress behavior.

\section{INTRODUCTION}

The suction foundation used in this study was originally designed for offshore drilling rigs, but suction foundations can be used for offshore wind turbines, which are subject to different stresses than drilling rigs. Offshore wind turbines are mainly affected by considerable bending moment and lateral force. Taiwan can benefit from offshore wind turbines, but because Taiwan is often struck by typhoons, the foundational stability of those offshore turbines must not be ignored. This study primarily considered suction foundations that can benefit the stability of operational offshore wind turbines off the coast of Taiwan; in particular, this study considered a plate structure added to the upper part of a suction foundation to improve the bearing area and enhance the bearing capacity. A composite suction foundation is illustrated in Fig. 1.

Academics have published voluminous research on suction foundations, such as the two-dimensional (2D) finite element method analyses of Bransby and Randolph [1], Bransby and Yun [2], Gourvenec [3], and Tani and Craig [4]. To understand the bearing capacity of the foundation, Zhan and Liu [5] performed a three-dimensional (3D) finite element method analysis of the axial and lateral friction impedance and the negative pressure generated by suction. In recent years, scholars have often compared suction barrel length $(L)$ and diameter $(D)$. Bransby and Yun [2] used finite element

Manuscript received November 22, 2016; revised May 1, 2017.

Yun-Chih Chiang is with the Center for General Education, Tzu Chi University, Hualien, Taiwan (e-mail: ycchiang@mail.tcu.edu.tw).

San-Shyan Lin, Sheng-Yu Chu, Hui-Ming Fang, Hsing-Yu Wang, and Sung-Shan Hsiao are with the Department of Harbor and River Engineering, National Taiwan Ocean University, Keelung, Taiwan (e-mail: sslin46@gmail.com, 10252060@mail.ntou.edu.tw, fred3618@gmail.com, hywang1108@gmail.com; sshsiao@mail.ntou.edu.tw). software and upper bound theory to analyze the bearing capacity of suction foundations and shallow foundations; they found that the soil inside the foundation could be deformed; thus, it must not be simulated as a rigid body. Gourvenec [3] used a 2D software simulation of a suction foundation to find that the lateral bearing capacity had a linear relationship with the buried depth of the foundation, and the maximum bending moment was proportional to the square of the depth ratio of the foundation. Zhan and Liu [5] used 3D finite element analysis software to simulate four forces (vertical, horizontal, moment, and torque) loaded on a foundation, and found that torque has a considerable effect on the axial bearing capacity, but torque has a much smaller effect on lateral bearing capacity, and the influence of torque on lateral bearing capacity is less than the relevant limit. Zhang et al. [6] used ABAQUS software to simulate deep-buried circular plate foundations with various ratios of thickness and diameter, and then calculated the proportion of the ultimate uniaxial bearing capacity and bending moment bearing capacity. Mana et al. [7] conducted a series of finite element simulations on how to optimize the soil bearing capacity of a suction bucket and categorized soils as homogeneous and normally compacted clays. Homogeneous clays were found in two of three walls, and for a six-walled body, the most compacted clays could form the basis of the predicted maximum bearing capacity.

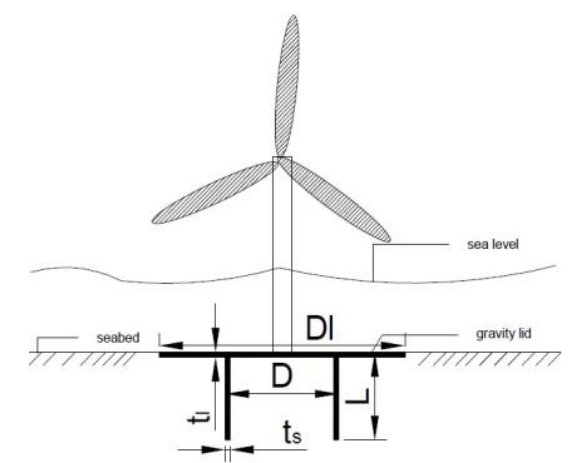

Fig. 1. Geometry of a composite suction foundation.

In this study, PLAXIS 3D finite element software was used to simulate the axial and lateral ultimate bearing capacities of suction foundations and composite suction foundations. The influence of different length-diameter ratios $(L / D=0.5,0.75$, 1) of the barrel on the suction and compound suction foundations was observed. On the basis of homogeneous saturated clay placed in a perfect elastoplastic model (Mohr Coulomb material model), the forces were loaded on the center of the circle. After calculation, the displacement of the center of the force-displacement diagram was used to determine the ultimate bearing capacity, the bending moment, 
and the rotation angle of the diagram. Finally, the lateral bearing capacity levels of composite suction foundations under different aspect ratios and eccentric loads were observed.

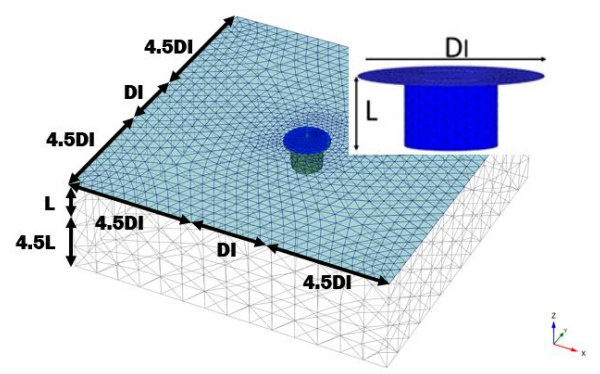

Fig. 2. Boundaries of the finite element model.

\section{FINITE ELEMENT MODEL}

When saturated clay is used for a short-term stability assessment, total stress analysis can be used rationally without draining, according to Tani and Craig [4]. The case of undrained water returns the model to Tresca destruction criteria: $\phi=0$, Young's modulus ( $E_{u}$ ) is set to $400 \times S_{u}$, and Poisson's ratio is set to 0.495 . To avoid singular values in the matrix, we did not use 0.5 as Poisson's ratio. The soil data used in this study were based on data from the Taiwan Generations Corporation [8] and regressed with the formula $S_{u}=0.1402 N$ to obtain an undrained shear strength of $S_{u}=5.8+1.78 z(\mathrm{kPa})$, where the saturated unit weight of the soil is $18.88 \mathrm{kN} / \mathrm{m}^{3}$ and the shear modulus $G$ is 967 . In the simulation, the undrained shear strength increased with increasing depth by $1.78 \mathrm{kPa}$ per meter to simulate the normal compaction of the clay; the software calculated the undrained shear strength $\left[S_{u}=10+1.78 z(\mathrm{kPa})\right]$ of the soil to compare the strength levels. The boundaries of the soil were defined as shown in Fig. 2, and the interface between the bucket body and the clay was set to increase the accuracy of the simulation results. The composite suction foundation simulated in this study is shown in Fig. 3, where the center of the upper cover was subjected to a turbine axial load of $1000 k N(V)$. For the simulations, the lateral load $(H)$ and bending moment $(M)$ were calculated as outputs; the diameter of the suction bucket was $D=12 \mathrm{~m}$. Four simulation runs were performed with the diameter of the upper plate cover set to 12, 16, 20, and $24 \mathrm{~m}$. The thickness of the bucket body was $t_{s}=0.004 \mathrm{D}$, and the thickness of the lid and the upper plate structure was $t_{l}=0.01 D$. To ensure that the upper plate structure was not deformed, the shear modulus $G$ was assumed to be 109 , and was represented as a rigid body. The input conditions of the model used in this study are shown in Table I.

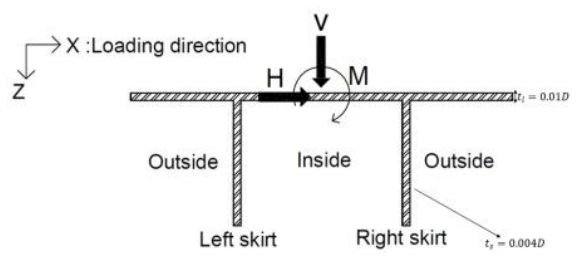

Fig. 3. Composite suction foundation loading schematic.
TABLE I: COMPOSITE SUCTION FOUNDATION PARAMETER DEFINITIONS

\begin{tabular}{llll}
\hline \hline Diameter of the upper lid, $D_{l}(m)$ & $12,16,20,24$ & \\
Material & Steel & \\
Buoyant unit weight $\left(k N / m^{3}\right)$ & 68 & \\
Elasticity Modulus of lid, $E(G P a)$ & $10^{9}$ & \\
Elasticity Modulus of skirt, $E(G P a)$ & 210 & & \\
Diameter of the suction bucket, $D(m)$ & 12 & & \\
Skirt length, $L(m)$ & 6 & 9 & 12 \\
$L / D$ & 0.5 & 0.75 & 1 \\
Skirt thickness, $t_{s}(m)$ & $0.004 D$ & \\
Lid thickness, $t_{l}(m)$ & $0.01 D$ & \\
\hline \hline
\end{tabular}

\section{NUMERICAL MODEL VALIDATION}

The results of the PLAXIS 3D simulation were compared with those of Hung and Kim [9]. The bearing capacity of the suction foundation was mainly determined by the frictional force of the bucket body. In a 3D simulation, the effect of the structure's shape and the interface strength between the soil and the structure should be considered. Previous studies have considered the aspect ratio $(L / D)$, usually not more than 1 , and assumed that the soil was homogeneous clay; displacement was applied in the suction center of the base and forces were calculated in the foundation. In the current study, the undrained shearing strength $S_{u}$ of homogeneous clay was assumed to be $5 \mathrm{kPa}$, Young's modulus $E_{u}$ was set to $400 \times S_{u}$, Poisson's ratio $v_{u}$ was set to 0.495 in the undrained condition, and the effective unit weight $\gamma^{\prime}$ of the clay was set to $6 \mathrm{kN} / \mathrm{m}^{3}$. Young's modulus for the suction foundation was assumed to be $E=E_{u} \times 10^{9}$, and the interface between the soil and the structure was assumed to be coarse relative to the soil as a rigid body. The separation effect of the soil and the structure was not considered here. The bucket lid thickness was assumed to be $t_{l}=0.01 \mathrm{D}$, the base barrel thickness was assumed to be $t_{s}=0.004 D$, and the distance to the soil boundary was assumed to be $B_{H} / D=4.5$ and $B_{V} / D=4.5$, meaning that the distance to the boundary was 4.5 times the base diameter. The suction barrel diameter was set at $10 \mathrm{~m}$ and simulations were run with $L / D=0,0.25,0.6$, and 1 for comparison. The final results showed the lateral load capacity of each aspect ratio as $H_{0} /\left(A \cdot S_{u}\right)$. Fig. 4 indicates that the lateral load capacity was normalized to produce an error. According to the PLAXIS 3D manual, the interface reduction factor $R_{i n}$ of the clay and steel structure was assumed to be 0.5 , and the error source may have been the interface strength between the soil and the structure.

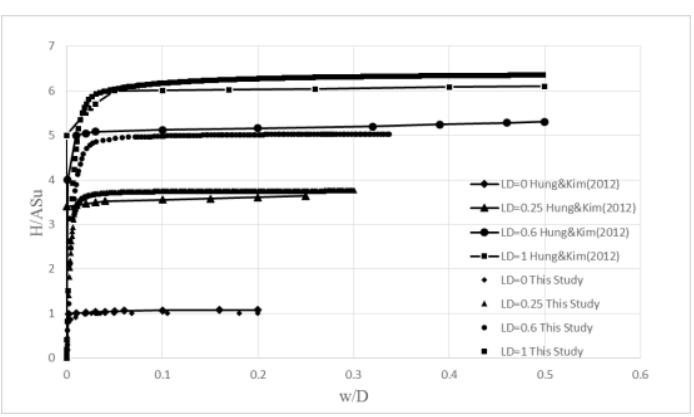

Fig. 4. Verification with [9]. 


\section{Simulation Results}

The soil conditions simulated in this study were divided into two cases: one was Fuhai clay, and the other was a harder clay based on Fuhai clay with $z=0$ and with an undrained shear strength of $4.2 \mathrm{kPa}$. With $D=12 \mathrm{~m}$, the barrel length was changed to give $L / D$ values of $0.5,0.75$, and 1 , and the diameter of the plate cover was varied to give $D l=12,16,20$, and $24 \mathrm{~m}$; the bearing capacities of the different parameter combinations were simulated with a $5 \mathrm{MW}$ turbine axial load $(V)$ of $10,000 \mathrm{kN}$, and load eccentricity values of $0,30,70$, and $100 \mathrm{~m}$. The lateral bearing capacity and the moment bearing capacity of the foundation were compared under two soil conditions. Fig. 5(a) shows the maximum lateral load capacity under various load eccentricity values when the diameter of the upper cover was $20 \mathrm{~m}$ and the bucket body diameter was 9 $\mathrm{m}$, and Fig. 5(b) shows the bending moment and angle. From these two pictures, it can be clearly observed that the higher the eccentric load is, the less the structure can withstand lateral force. Without bending moment, the structure can withstand lateral force more than it can withstand other forces, such as eccentric load.

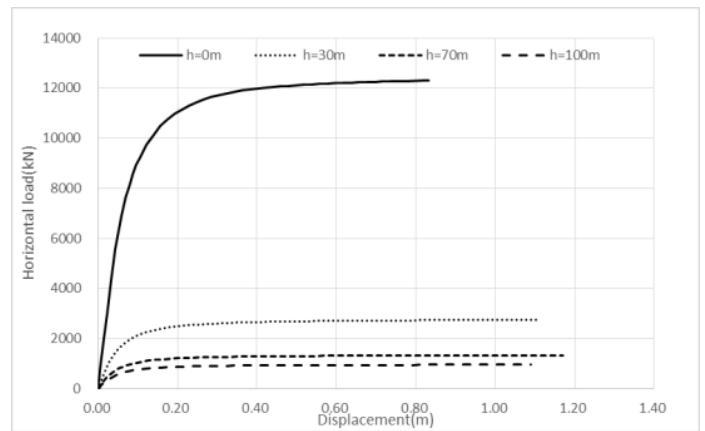

(a) Horizontal load-displacement interaction diagram

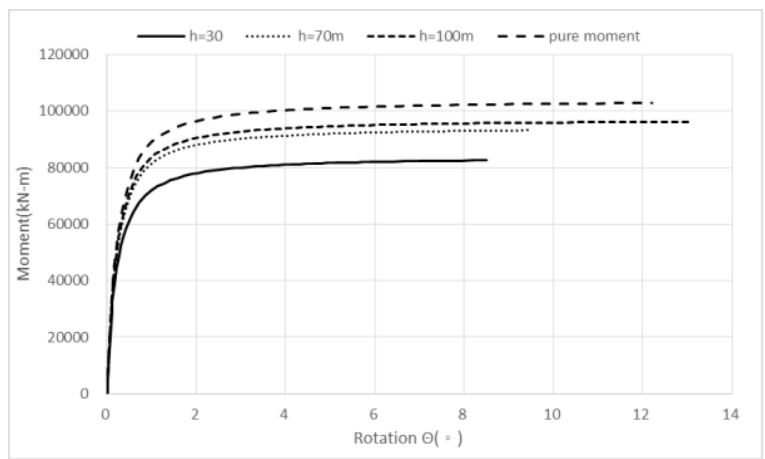

(b) Moment-rotation interaction diagram

Fig. 5. Upper lid diameter $D l=20 \mathrm{~m}, L / D=0.75$, with different load eccentricity $h$ in Fuhai clay.

Fig. 6 shows the total stress of the bucket inside and outside the bucket wall damage in the soil. The walls of the suction barrel were simulated in vertical slices; along the central lines of those vertical slices, the total stress changed to $L=9 \mathrm{~m}$ in the case of eccentric load $h=30 \mathrm{~m}$; the total stress distributions were calculated for plate diameter values $D I=12,16,20$, and $24 \mathrm{~m}$. A rotation center was generated at approximately $7 \mathrm{~m}$. As the diameter increased, the center of rotation was slightly displaced upward, representing an increase in bending moment resistance.

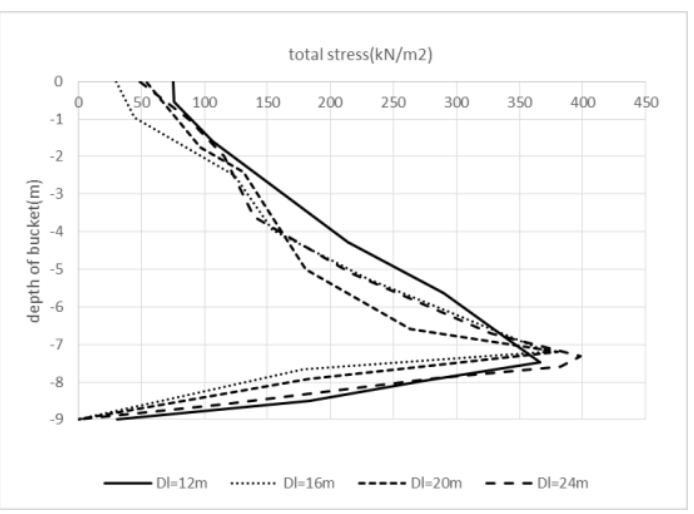

(a) Right skirt exterior total stress distribution

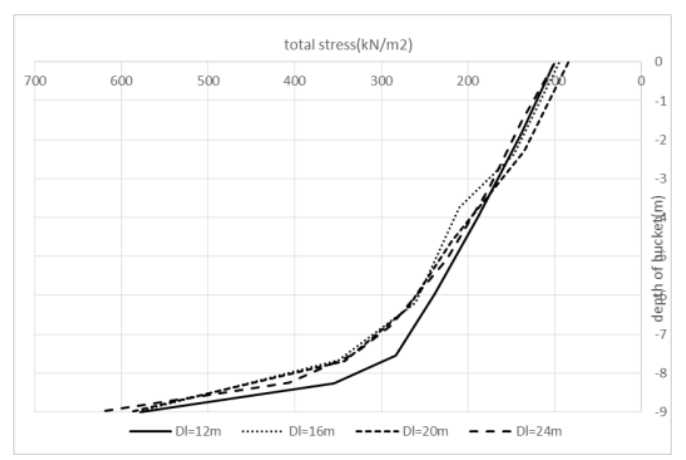

(b) Right skirt interior total stress distribution

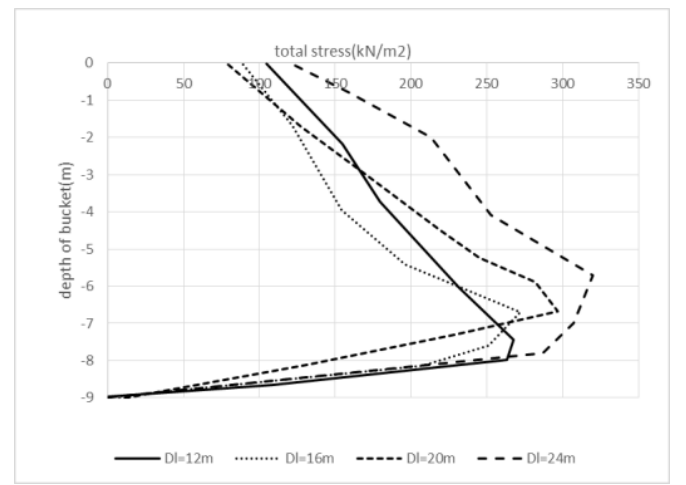

(c) Left skirt interior total stress distribution

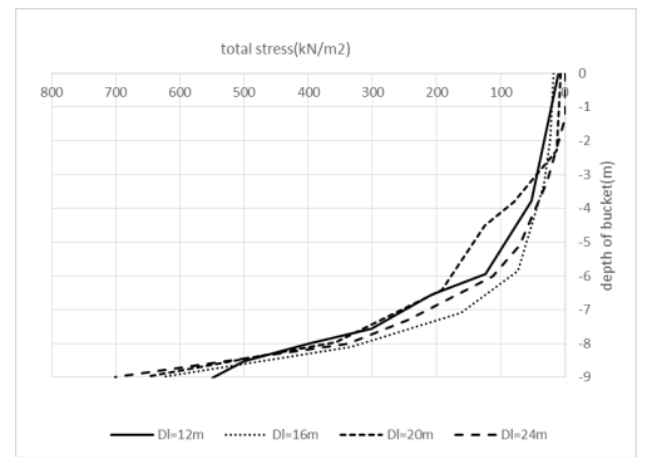

(d) Left skirt exterior total stress distribution

Fig. 6. Composite suction foundation with different $D l$ values (when bucket length $L=9 \mathrm{~m}$, load eccentricity $h=30 \mathrm{~m}$ ).

Fig. 7 illustrates the displacements of the composite suction foundation for $D l=12 \mathrm{~m}$ [Fig. $7(\mathrm{a}-\mathrm{c})]$ and $D l=24 \mathrm{~m}$ [Fig. 7(d-f)] under the two conditions of the destruction mechanism control chart. As Fig. 7(a) shows, when the cover plate $D l=12 \mathrm{~m}$ and $L / D=0.5$, the bucket must tilt, but there must also be some horizontal movement; the soil on the right side of the bucket body is notably displaced relative to the left soil. Consequently, the left side of the barrel body must separate from the soil. Fig. 7(b) and 7(c) shows that the bottom of the 
bucket at the center of the cylinder must produce a base rotation center at $L / D=0.75$ and $L / D=1$, and passive destruction must occur for a central point above the bucket, whereas an opposite point must experience active destruction. Fig. 7(d-f) illustrates that the cover plate must have a greater displacement than the foundation; if a force operates in the direction of dumping, the base of the rotation center point is even higher than the upper cover plate $(D l=12 \mathrm{~m})$ rotation center position. This shows that the composite suction foundation with $D l=24 \mathrm{~m}$ has a higher bending moment resistance than the foundation with $D l=12 \mathrm{~m}$.

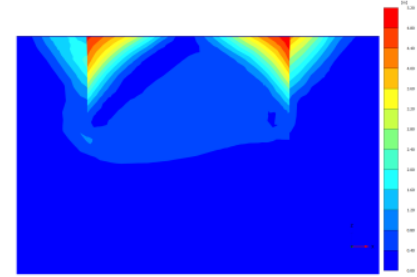

(a) $D l=12 \mathrm{~m}, L / D=0.5$

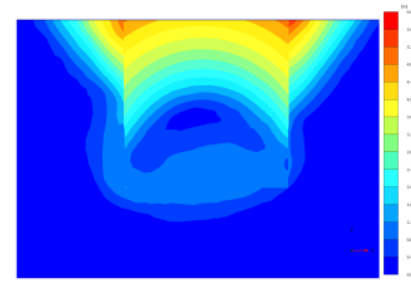

(c) $D l=12 \mathrm{~m}, L / D=1$

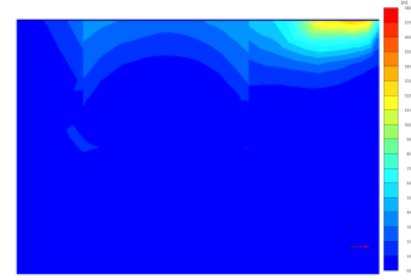

(e) $D l=24 \mathrm{~m}, L / D=0.75$

Fig. 7. Comparison of displacements of the composite suction foundation for upper lid diameter $D l=12 \mathrm{~m}, 24 \mathrm{~m}$ with different bucket $L / D$ values when load eccentricity $h=70 \mathrm{~m}$ in Fuhai clay.

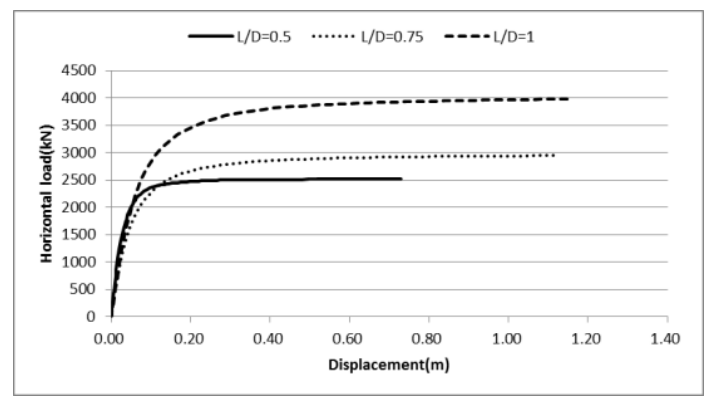

(a) Fuhai clay

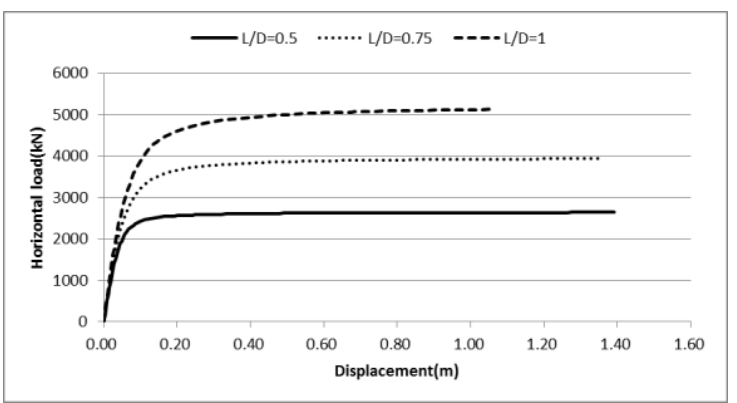

(b) Harder clay
Fig. 8. Horizontal load-displacement interaction diagram (upper lid diameter $D l=20 \mathrm{~m}$, load eccentricity $h=30 \mathrm{~m}$, with different bucket lengths).

Fig. 8(a) shows lateral horizontal load-displacement interaction results for structures in Fuhai clay. With a fixed superstructure diameter $D l=20 \mathrm{~m}$ and an eccentric load fixed at $30 \mathrm{~m}$, the length of the suction bucket was simulated for $\mathrm{L}=6$, 9 , and $12 \mathrm{~m}$; the maximum lateral force bearing capacity results were compared. When the base center displacement was $0.7 \mathrm{~m}$ and the length of the suction bucket was $L=6 \mathrm{~m}$, the lateral bearing capacity was approximately $2,523 \mathrm{kN}$. When $L=9 \mathrm{~m}$, the lateral bearing capacity increased by $15.7 \%$; from $9 \mathrm{~m}$ to $12 \mathrm{~m}$ the increase was $34.4 \%$. Fig. 8(b) shows corresponding results with harder clay. When the base center displacement was $0.7 \mathrm{~m}$ and the length of the suction bucket was $L=6 \mathrm{~m}$, the lateral bearing capacity was approximately $2,629 \mathrm{kN}$. When $L=9 \mathrm{~m}$, the lateral bearing capacity increased by $48.3 \%$; from $9 \mathrm{~m}$ to $12 \mathrm{~m}$ the increase was $30.0 \%$.

Fig. 9(a) shows the foundation lateral horizontal load-displacement interaction diagram for Fuhai clay. For values of the upper plate structure diameter $D I=12,16,20$, and $24 \mathrm{~m}$, the eccentric load was fixed at $30 \mathrm{~m}$, the suction bucket length was fixed at $L=9 \mathrm{~m}$, and the maximum lateral force bearing capacities of the structure were compared. When the base center displacement was $0.7 \mathrm{~m}$, the maximum lateral bearing capacity of the upper plate structure with diameter $D I=12 \mathrm{~m}$ was approximately $1,335 \mathrm{kN}$; when the diameter was increased to $16 \mathrm{~m}$, the lateral bearing capacity increased by $56.4 \%$; when the diameter was increased from $16 \mathrm{~m}$ to $20 \mathrm{~m}$, the maximum lateral bearing capacity increased by $30.4 \%$; when the diameter was increased from $20 \mathrm{~m}$ to $24 \mathrm{~m}$, the maximum lateral bearing capacity increased by $16.3 \%$. Fig. 9(b) shows results for harder clay. When the base center displacement was $0.7 \mathrm{~m}$, the bearing capacity with $D 1=12 \mathrm{~m}$ was approximately $1,863 \mathrm{kN}$; when the diameter was increased to $16 \mathrm{~m}$, the lateral bearing capacity was increased by $48.8 \%$; when the diameter was increased from $16 \mathrm{~m}$ to $20 \mathrm{~m}$, the maximum lateral bearing capacity increased by $40.6 \%$; when the diameter was increased from $20 \mathrm{~m}$ to $24 \mathrm{~m}$, the maximum lateral bearing capacity increased by $31.7 \%$.

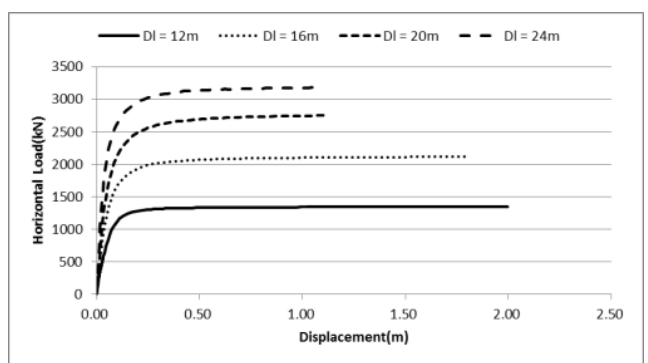

(a) Fuhai clay

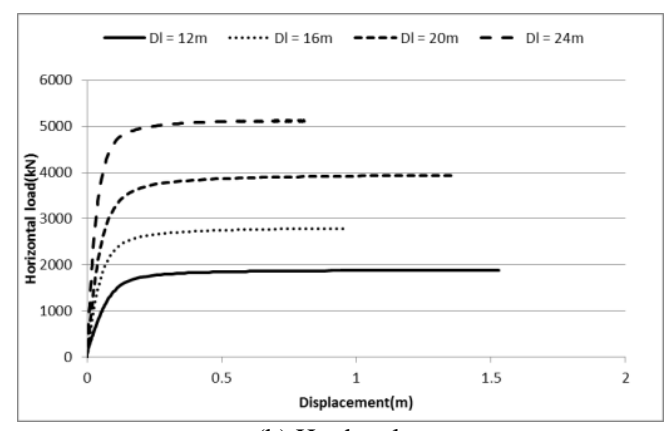

(b) Harder clay 
Fig. 9. Horizontal load-displacement interaction diagram $(L / D=0.75$, load eccentricity $h=30 \mathrm{~m}$, with different upper lid diameter $D l$ ).

Fig. 10(a) shows the foundation lateral moment-rotation interaction diagram for Fuhai clay. The diameter of the upper structure was fixed at $D l=20 \mathrm{~m}$, the eccentric load was $h=30 \mathrm{~m}$, and the rotation angles of different suction bucket lengths ( $L=6,9$, and $12 \mathrm{~m} ; L / D=0.5,0.75$ and 1 ) were compared. When the rotation angle of the foundation was $4^{\circ}$, the moment capacity of the suction bucket with a length of $6 \mathrm{~m}(L / D=0.5)$ was $74,600 \mathrm{kN}-\mathrm{m}$; when the length was $9 \mathrm{~m}(L / D=0.75)$, the moment capacity was $86,800 \mathrm{kN}-\mathrm{m}$; when the length was increased from $6 \mathrm{~m}$ to $9 \mathrm{~m}$, the moment bearing capacity increased by $16.4 \%$; when the length was increased from $9 \mathrm{~m}$ to $12 \mathrm{~m}$, the moment capacity increased by $35.9 \%$. Fig. 10 (b) shows results for harder clay; for a suction bucket with a length of $6 \mathrm{~m}(L / D=0.5)$, the moment capacity was $77,960 \mathrm{kN}-\mathrm{m}$; for a length of $9 \mathrm{~m}(L / D=0.75)$, it was $115,536 \mathrm{kN}-\mathrm{m}$; when the length was increased from $6 \mathrm{~m}$ to $9 \mathrm{~m}$, the moment bearing capacity increased by $48.2 \%$; when the length was increased from $9 \mathrm{~m}$ to $12 \mathrm{~m}$, the moment capacity increased by $31.0 \%$.

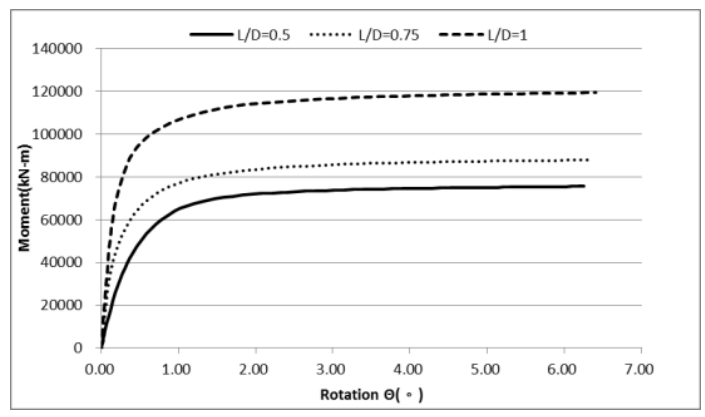

(a) Fuhai clay

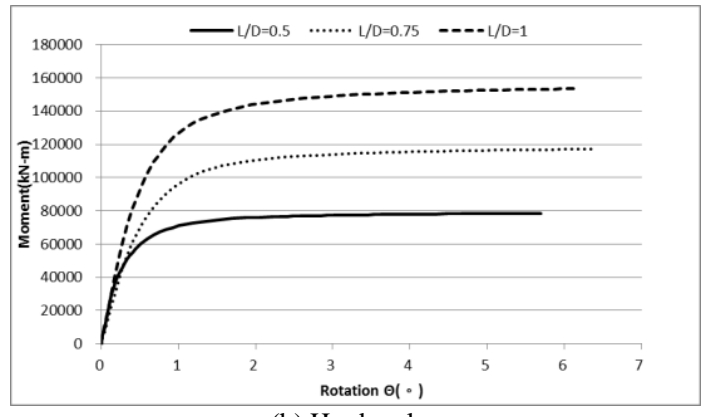

(b) Harder clay

Fig. 10. Moment-rotation interaction diagram (upper lid diameter $D l=20 \mathrm{~m}$, load eccentricity $h=30 \mathrm{~m}$, with different bucket lengths).

Fig. 11(a) shows the lateral moment-rotation interaction diagram for Fuhai clay. The suction bucket length was fixed at $L=9 \mathrm{~m}$, the eccentric load was fixed at $30 \mathrm{~m}$, and various cover plate diameter values $(D l=12,16,20$ and $24 \mathrm{~m})$ were compared. When the rotation angle of the foundation was $4^{\circ}$ with a diameter $D l=12 \mathrm{~m}$, the bearing capacity of the top cover was $39,594 \mathrm{kN}-\mathrm{m}$. For $D l=16 \mathrm{~m}$, the bearing capacity was $62,209 \mathrm{kN}-\mathrm{m}$. For $D l=20 \mathrm{~m}$, the bearing capacity was $86,786 \mathrm{kN}-\mathrm{m}$. For $D l=24 \mathrm{~m}$, the bearing capacity was $93,740 \mathrm{kN}-\mathrm{m}$. When the diameter was increased from $12 \mathrm{~m}$ to $16 \mathrm{~m}$, the moment bearing capacity increased by $57.1 \%$; for a diameter increase from $16 \mathrm{~m}$ to $20 \mathrm{~m}$, the moment bearing capacity increased by $39.5 \%$; for a diameter increase from $20 \mathrm{~m}$ to $24 \mathrm{~m}$, the moment bearing capacity increased by $8.0 \%$.
Fig. 11(b) shows results for harder clay. The bearing capacity for a top cover diameter $D l=12 \mathrm{~m}$ was $55,501 \mathrm{kN}-\mathrm{m}$. For $D l=16 \mathrm{~m}$, the bearing capacity was $82,454 \mathrm{kN}-\mathrm{m}$. For $D l=20 \mathrm{~m}$, the bearing capacity was $115,528 \mathrm{kN}-\mathrm{m}$. For $D l=24 \mathrm{~m}$, the bearing capacity was $153,140 \mathrm{kN}-\mathrm{m}$. When the diameter was increased from $12 \mathrm{~m}$ to $16 \mathrm{~m}$, the moment bearing capacity increased by $48.6 \%$. When the diameter was increased from $16 \mathrm{~m}$ to $20 \mathrm{~m}$, the moment bearing capacity increased by $40.1 \%$. When the diameter was increased from $20 \mathrm{~m}$ to $24 \mathrm{~m}$, the moment bearing capacity increased by $32.6 \%$.

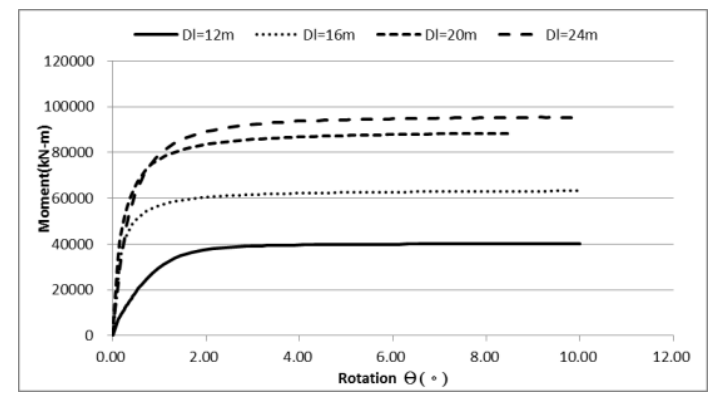

(a) Fuhai clay

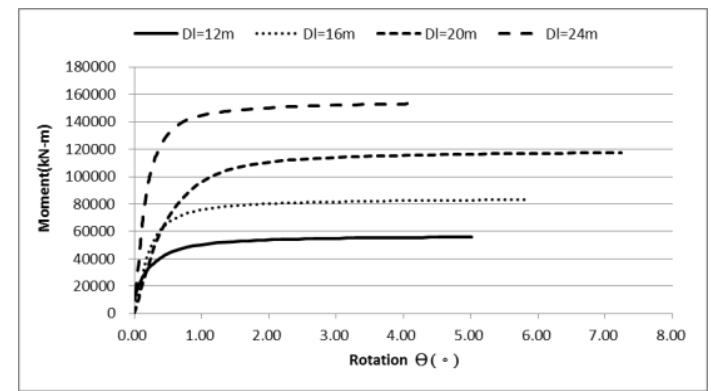

(b) Harder clay

Fig. 11. Moment-rotation interaction diagram $(L / D=0.75$, load eccentricity $h=30 \mathrm{~m}$, with different upper lid diameter $D l$ ).

\section{CONCLUSION}

In this study, finite element software (PLAXIS 3D) was used to analyze the bearing capacities of composite suction foundations. A quadrilateral element was used in the finite element mesh. The simulation results of changing the diameter of the upper plate structure, the length of the suction bucket $(L / D)$, and loading position showed that the proposed structure can be considerably superior to a traditional suction-type foundation. Simulations of Fuhai and harder clays showed that the bearing capacity of a composite suction foundation was absolutely related to the undrained shear strength $\left(S_{u}\right)$ of the clay. The lateral bearing capacity and the moment bearing capacity increased with the undrained shearing strength.

In a composite suction foundation, the maximum lateral bearing capacity increased as the suction bucket length increased when the diameter remained constant (thus the $L / D$ changed). The maximum lateral bearing capacity of the composite suction foundation increased with the diameter of the upper structure. When the length of the suction bucket of the composite suction foundation was increased, the bending moment resistance of the compound suction foundation increased, and the base rotation angle decreased with the length of the suction bucket. 
The results of this study showed that the composite suction foundation was superior to the traditional suction foundation in lateral bearing capacity and bending moment resistance. Composite suction foundations retained the advantages of suction foundations, and demonstrated greater effectiveness at withstanding natural forces. No sensitivity study on the size of the mesh was performed. However, close agreement was observed between this study and other available numerical results, based on the size of the mesh used in the numerical simulations. This study is applicable to composite suction foundations in severe environmental conditions, and provides reference information for offshore wind turbines.

\section{REFERENCES}

[1] M. F. Bransby and M. F. Randolph, "Combined loading of skirted foundations," Géotechnique, vol. 48, no. 5, pp. 637-655, 1998.

[2] M. F. Bransby and G. Yun, "The undrained capacity of skirted strip foundation under combined loading," Géotechnique, vol. 59, no. 2, pp. $115-125,2009$.

[3] S. Gourvenec, "Effect of embedment on the undrained capacity of shallow foundations under general loading," Géotechnique, vol. 58, no. 3, pp. 177-185, 2008.

[4] K. Tani and W. H. Craig, "Bearing capacity of circular foundation on soft clay of strength increasing with depth," Soils and Foundations, vol. 35, no. 4, pp. 21-35, 1995.

[5] Y. G. Zhan and F. C. Liu, "Numerical analysis of bearing capacity of suction bucket foundation for offshore wind turbines," Electronic Journal of Geotechnical Engineering, vol. 15, pp. 633-644, 2010.

[6] Z. L. Zhang, M. Hauge, and C. Thaulow, "The effect of T stress on the near tip stress field of an elastic-plastic interface crack," ICF 9-Sydney, Australia-1997. 2012.

[7] Mana, S. K. Divya, Susan Gourvenec, and Mark F. Randolph, "Experimental investigation of reverse end bearing of offshore shallow foundations," Canadian Geotechnical Journal, vol. 50, no. 10, pp. 1022-1033, 2013.

[8] Taiwan Generations Corp., Fuhai offshore wind power project submarine cable routing survey and wind field site geology and geophysical exploration work" wind farm site geological drilling and test results report, 2012.

[9] L. C. Hung and S. R. Kim, "Evaluation of vertical and horizontal bearing capacities of bucket foundations in clay," Ocean Eng., vol. 52, pp. $75-82,2012$.

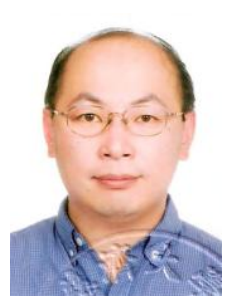

Yun-Chih Chiang received the Ph.D. degree in 2009, the Department of Engineering Science and Ocean Engineering, National Taiwan University. Currently in the Center for General Education (Tzu Chi University, Taiwan) as an associate professor.

The research interests include coastal engineering, sediment transport, topography changes, nearshore hydrodynamics and the ocean renewable energy.

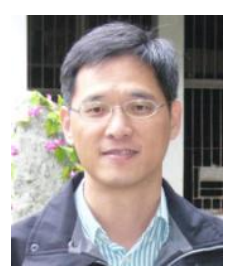

San-Shyan Lin received the Ph.D. degree in the University of Washington, Missouri. Now is a professor at the Department of Harbor and River Engineering, National Taiwan Ocean University, and taught for nearly three decades.

The research interests include Deep foundation engineering, Earthquake Engineering and the Geological Engineering Materials.

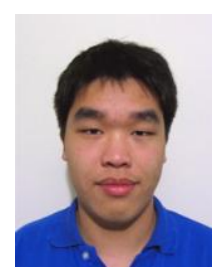

Sheng-Yu Chu received the master degree in 2015, the Department of Harbor and River Engineering, National Taiwan Ocean University.

The learning interests and expertise are soil mechanics, basic engineering and numerical analysis.

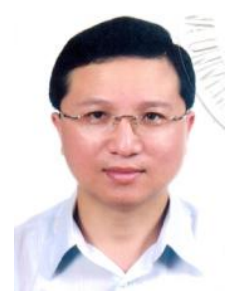

Hui-Ming Fang received the Ph.D. degree in 2008 , the Department of Harbor and River Engineering, National Taiwan Ocean University. Currently in the same university as an assistant professor.

The research interests include ocean engineering, oceanographic measurements, coastal protection, disaster prevention and management, and cloud computing.

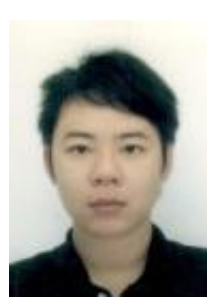

Hsing-Yu Wang received the master degree in 2009, the Department of Harbor and River Engineering, National Taiwan Ocean University. And continue to a doctorate, now is a Ph.D. candidate.

The learning interests and expertise are coastal engineering, sediment transport, topography changes, oceanographic measurements and coastal environment management.

Sung-Shan Hsiao is a professor at the Department of Harbor and River Engineering, National Taiwan Ocean University, and taught for nearly three decades. Our goal is to educate students to become both a theoretical and practical engineers. And aims to engage with the major national construction and development of marine science and technology.

The research interests and expertise about sediment transport, oceanographic measurements, nearshore hydrodynamics and coastal environment management. 